Original Article

\title{
Expression of brain-derived neurotrophic factor, IGF-1 and cortisol elicited by regular aerobic exercise in adolescents
}

\author{
Yong Kyun JEON ${ }^{1)}$, Chang Ho HA ${ }^{2,3)^{*}}$ \\ 1) Department of Physical Education, Dankook University, Republic of Korea \\ 2) Institute of Social Physical Education, Dongguk University, Republic of Korea \\ 3) Department of Human Performance and Leisure Studies, North Carolina A\&T State University:
} 1601 E, Market Street, Greensboro NC 27411, USA

\begin{abstract}
Purpose] This study was conducted on adolescent subjects whose brains are still developing with the purpose of identifying the effect of 8 weeks duration of aerobic exercises on the expression of BDNF, IGF-1 and cortisol, to identify effect of aerobic exercise on the expression of cortisol, BDNF and IGF-1 related to nerve cell growth. [Subjects and Methods] The subjects were 20 junior-high school students with no history of physical illness. The students were divided into an exercise group and a control group. The exercise group performed 3 treadmill exercise times per week for 8 weeks. The exercise time for the consumption of $200 \mathrm{kcal}$ was calculated and the exercises were performed by each individual for 8 weeks. [Results] The exercise group showed statistically significant in increases serum BDNF and IGF-1 after 8 weeks, but cortisol showed no significant change. There were statistically significant differences between the groups in serum BDNF and IGF-1 after 8 weeks, but the difference in cortisol levels was not significant. [Conclusion] We found that long-term regular aerobic exercises has a positive effect on the enhancement of serum BDNF levels at rest and IGF-1 of adolescents who are still undergoing through brain developments.

Key words: Aerobic exercise, Adolescents, BDNF
\end{abstract}

(This article was submitted Aug. 27, 2014, and was accepted Oct. 21, 2014)

\section{INTRODUCTION}

Brain-Derived Neurotrophic Factor (BDNF) is a neurotrophic factor that appears throughout the mammalian central nervous system ${ }^{1)}$.

It is frequently found in the hippocampus of the brain (hippocampal formation), as well as in the cerebral cortex and amygdalus. BDNF is reported to affect learning ability and memory, as it operates in the areas that regulate neuronal growth, and repair and neuroplasticity. It is also a feature of the brain during brain formation before birth and its influence continues through adolescence ${ }^{2-4)}$.

BDNF is reported to be an important material for the growth and development of nerve cells in different areas both within and outside of the brain, increasing resistance to damage and improving the survival of neurons ${ }^{1)}$. It is a key factor in growth and differentiation during neural development, and is often used as an index to measure the impact of exercise on the rehabilitation of damaged nerves. It is further

\section{*Corresponding author. Chang Ho Ha (E-mail:} changhoha00@gmail.com)

C2015 The Society of Physical Therapy Science. Published by IPEC Inc. This is an open-access article distributed under the terms of the Creative Commons Attribution Non-Commercial No Derivatives (by-ncnd) License $<$ http://creativecommons.org/licenses/by-nc-nd/3.0/> . reported that both exercise and learning induce growth of the motor cortex, increase in hippocampal BDNF, and increase in the plasticity of the brain, which in turn induces development of the cell body and axon of the associated neurons ${ }^{5-7)}$.

BDNF expression in the hippocampus has been reported to improve the production and survival of brain cells ${ }^{8)}$, and BDNF expression is reported to be stimulated by exercise $^{6,9,10)}$. It has also been reported that exercise has a positive impact on BDNF expression in the animal brain ${ }^{11)}$.

For young people, increases in BDNF induced by aerobic exercises would enhance neuronal growth and development in the hippocampus, which would in turn enhance cognitive ability, learning ability and memory, greatly improving educational performance. Therefore exercise is considered to be essential for the development of the adolescent brain.

Insulin-like growth factor 1 (IGF-1), one of the factors involved in BDNF expression, is known to mediate regulation of genes involved in BDNF-related neurogenesis ${ }^{12)}$, and it is involved in the growth and differentiation of neuron units of the brain ${ }^{13)}$. In association with exercise, IGF-1 increases in both the brain and peripheral nerves after exercise and neurotransmitters are also increased in the blood vessels ${ }^{14}$. On the other hand, psychological stress has negative effects on nerve cells and heightened stress reduces BDNF mRNA expression $^{6}$.

A fast-paced lifestyle, coupled with education policy and environmental changes in South Korea are thought to have 
increased the psychological stress of the Korean youth population. Cortisol is a typical stress hormone. Corticotrophinreleasing factor (CRF) is secreted by the hypothalamus, which in turn induces the release of adrenocorticotrophic hormone (ACTH) from the anterior pituitary. ACTH induces cortisol secretion into the adrenal cortex via the bloodstream.

Cortisol is released not only in response to psychological stress, but also as a product of the energy generation required for exercises. With exercise, cortisol is released through the hypothalamic-pituitary-adrenal axis into the circulation of the human body. Cortisol, which is one of the major corticosteroids, plays a role in the conversion of glycogen in muscles and the liver into blood glucose, or fats into fatty acids for the purpose of metabolic energy production. Also, cortisol responds sensitively to self-defensive stimuli such as psychological oppression, anxiety, or fear, similar to the response to energy generation for the stimulation of movement. The relationship between stress and BDNF mRNA (messenger ribonucleic acid) reveals that increased stress will lower the level of BDNF expression ${ }^{6}$ and significantly disturbs the creation of the nerve cells in the hippocampus ${ }^{15)}$. Zheng et al. reported that BDNF and cortisol have a negative correlation $^{16)}$.

Most previous studies of BDNF have used experimental animals and many of their results correlate with a particular disease. In those experiments, animals were forced to perform aerobic exercises, with stress induced for the initiation and maintenance of the exercising condition. When these animals are given a stimulating stressor, such as electrical shocks or swimming as exercise, the stress elicits strong instincts to escape and initiates changes in the peripheral circulation. It also activates circulation in the central brain, thus affecting the whole body. In addition to the need to use a stressor to initiate exercise conditions in animals, the results use of these animal models have obvious limitations regarding their application to the human body. In order to investigate the effect of cortisol on the expression of BDNF and IGF-1 through aerobic exercise, such experiments must ultimately be carried out using voluntary exercises performed by human subjects, negating the need for stress induced exercise states which can confound results. Previous studies have not yet sufficiently proved the relationship of cortisol expression and nerve cell growth in response to aerobic exercise, as well as the involvement of BDNF and IGF-1.

The purpose of this study was therefore, to identify effect of aerobic exercise on the expression of cortisol, BDNF and IGF-1 related to nerve cell growth.

\section{SUBJECTS AND METHODS}

Twenty healthy junior high school students, who did not regularly exercise and were not previously diagnosed as having abnormal glucose metabolism volunteered to participate in the study.

This study was approved and reviewed by the Institutional Review Board of the Human Care and Use Committee of the Exercise Physiology Research Institute of Dankook University, and written consent forms were obtained from all of the subjects' parents.
Table 1. The characteristics of the subjects (M $\pm \mathrm{SD})$

\begin{tabular}{lcccc}
\hline $\begin{array}{l}\text { Variables } \\
\text { group }\end{array}$ & $\begin{array}{c}\text { Age } \\
(\mathrm{yrs})\end{array}$ & $\begin{array}{c}\text { Height } \\
(\mathrm{cm})\end{array}$ & $\begin{array}{c}\text { Body weight } \\
(\mathrm{kg})\end{array}$ & \%fat \\
\hline $\mathrm{EG}(\mathrm{n}=10)$ & 15 & $161.2 \pm 2.5$ & $56.3 \pm 6.8$ & $19.8 \pm 4.6$ \\
$\mathrm{CG}(\mathrm{n}=10)$ & 15 & $162.6 \pm 3.4$ & $55.7 \pm 7.7$ & $18.9 \pm 3.8$ \\
\hline
\end{tabular}

EG: exercise group, CG: control group

Table 2. Baseline values of BDNF, IGF-1, and cortisol in EG and $\mathrm{CG}$

\begin{tabular}{lcc}
\hline \multirow{2}{*}{ Variables } & $\mathrm{EG}(\mathrm{n}=10)$ & $\mathrm{CG}(\mathrm{n}=10)$ \\
\cline { 2 - 3 } & $\mathrm{M} \pm \mathrm{SD}$ & $\mathrm{M} \pm \mathrm{SD}$ \\
\hline BDNF $(\mathrm{pg} / \mathrm{ml})$ & $23,321.7 \pm 6,247.0$ & $24,071.3 \pm 6,139.2$ \\
IGF-1 $(\mathrm{ng} / \mathrm{ml})$ & $397.1 \pm 131.1$ & $420.0 \pm 172.3$ \\
Cortisol $(\mu \mathrm{g} / \mathrm{dL})$ & $13.6 \pm 4.1$ & $14.5 \pm 4.6$ \\
\hline
\end{tabular}

EG: exercise group, CG: control group

There were no significant differences (independent t-test)

BDNF, IGF-1, and cortisol levels of all the subjects were measured at the start of the study. After baseline measurement, the subjects were randomly assigned an exercise group $(\mathrm{n}=10)$ or a control group $(\mathrm{n}=10)$. The characteristics of the subjects are shown in Table 1.

The exercise group participated in 8 weeks of supervised aerobic exercise training. The exercise group trained for 3 days a week for 8 weeks, while the control group was asked to continue their normal sedentary activities. Maximal oxygen uptake (VO2max) of all the exercise group participants was measured in order to prescribe aerobic exercise intensity for the purpose of the intervention.

The exercise group subjects were instructed to maintain a typical diet and a particular activity pattern throughout the study, while the subjects in the control group were asked to continue their daily normal and sedentary activities.

Pre-assessment blood samples were obtained 2 days before, and 2 days after the end of the exercise intervention for the assessment of BDNF, IGF-1, and cortisol (Table 2).

Maximal oxygen uptake (VO2max) was measured using a computerized metabolic (Quinton, USA) and a modified Bruce protocol at Dankook University fitness center, Korea. Graded exercise assessment was stopped once subjects attained an RER $\geq 1.10$ or if subjects indicated that they wished to stop the test ${ }^{17)}$.

Whole blood was centrifuged at 3,000 rpm for 15 minutes and to separate it into serum and plasma. The blood was stored at $-80^{\circ} \mathrm{C}$ until analysis.

BDNF concentration was measured using an ELISA kit (sandwich enzyme-linked immunosorbant assay). IGF-1 and cortisol were measured using a $\gamma$-counter (Cobra-5010 Quantum, Packard, USA).

Elisa Kits (Promega, USA), IGF-I-RIA-CT Kits (Toshiba YBA-200 FRNEO, Japan) and Coat-A-Count Cortisol Kits (Siemens, USA) were used to determine the concentrations of BDNF ( $\mathrm{pg} / \mathrm{mL})$, IGF-1 ( $\mathrm{ng} / \mathrm{mL})$ and cortisol $(\mathrm{ng} / \mathrm{mL})$, respectively.

The exercise program of this study consisted of an 8-week, 3 days a week aerobic exercise regimen at Dankook 
Table 3. The results of the paired t-test for BDNF, IGF-1, and a cortisol

\begin{tabular}{llcc}
\hline \multirow{2}{*}{ Variables } & \multirow{2}{*}{ Group } & Pre-test & Post-test \\
\cline { 3 - 4 } & & $(\mathrm{M} \pm \mathrm{SD})$ & $(\mathrm{M} \pm \mathrm{SD})$ \\
\hline $\mathrm{BDNF}$ & EG & $23,321.7 \pm 6,247.0$ & $27,566.0 \pm 5,647.6^{* * *}$ \\
$(\mathrm{pg} / \mathrm{ml})$ & CG & $24,071.3 \pm 6,139.2$ & $24,921.2 \pm 7,821.5$ \\
$\mathrm{IGF}-1$ & EG & $397.1 \pm 131.1$ & $596.6 \pm 104.1^{*}$ \\
$(\mathrm{ng} / \mathrm{ml})$ & $\mathrm{CG}$ & $420.0 \pm 172.3$ & $432.3 \pm 165.2$ \\
Cortisol & EG & $13.6 \pm 4.1$ & $11.2 \pm 2.3$ \\
$(\mu \mathrm{g} / \mathrm{dL})$ & $\mathrm{CG}$ & $14.5 \pm 4.6$ & $15.3 \pm 4.3$ \\
\hline
\end{tabular}

Values are means \pm SD

EG: exercise group, CG: control group

*: significantly different within group by the paired t-test, ${ }^{*}: \mathrm{p}<$ $0.05, * * *: \mathrm{p}<0.001$

University fitness center in Gyeonggi-do, Korea. Pre-test VO2max, maximal heart rate (HRmax), and resting heart rates (HRrest) were measured by ECG supporting a computerized metabolic (Quinton, USA).

Exercise was performed on treadmills and the exercise intensity was set between $40 \%$ and $60 \% \mathrm{VO}_{2} \mathrm{R}$ based on the scale recommended by $\mathrm{ACSM}^{17)}$. In order to standardize the work performed, exercise time was individually prescribed so that each subject burned $200 \mathrm{kcal}$ in an exercise session.

During the testing and intervention periods, all subjects were asked not to undertake any exercise other than the ones designed for the experiments, with cooperation from their schools.

All the results of this study are presented as mean \pm standard deviation. The independent t-test was performed to examine differences in baseline characteristics of the subjects between the 2 groups. The paired t-test was performed to examine the changes between pre- and post-intervention in each group. Statistical significance was chosen as $\mathrm{p}<0.05$, and all analyses were performed using SPSS version 18.0 (SPSS, Chicago, IL, USA).

\section{RESULTS}

The changes in BDNF, IGF-1 and cortisol after exercising 3 days per week for 8 weeks are shown in Table 3.

After performing 8 weeks of aerobic exercise, the change in BDNF of the exercise group was significant $(\mathrm{p}<0.01)$, increasing from $23,321.7 \pm 6,247.0 \mathrm{pg} / \mathrm{ml}$ to $27,566.0 \pm$ $5,647.6 \mathrm{pg} / \mathrm{ml}$. The change in IGF-1 was also significant $(\mathrm{p}<$ 0.05 ), increasing from $420.0 \pm 172.3 \mathrm{ng} / \mathrm{ml}$ to $432.3 \pm 165.2$ $\mathrm{ng} / \mathrm{ml}$. The change in cortisol, however, was not significant, declining from $13.6 \pm 4.1 \mu \mathrm{g} / \mathrm{dL}$ to $11.2 \pm 2.3 \mu \mathrm{g} / \mathrm{dL}$. The control group did not show any significant differences in BDNF, IGR-1 or cortisol between pre- and post-intervention.

The differences in BDNF, IGF-1 and cortisol after exercise are shown in Table 4.

\section{DISCUSSION}

Research has been actively conducted on changes in the secretion of BDNF as it relates to brain function, so it is well known that BDNF is secreted in peripheral veins and
Table 4. The significance of differences (independent t-test) between EG and CG after 8 weeks of exercise

\begin{tabular}{lcc}
\hline \multirow{2}{*}{ Variables } & $\mathrm{EG}(\mathrm{n}=10)$ & $\mathrm{CG}(\mathrm{n}=10)$ \\
\cline { 2 - 3 } & $\mathrm{M} \pm \mathrm{SD}$ & $\mathrm{M} \pm \mathrm{SD}$ \\
\hline BDNF $(\mathrm{pg} / \mathrm{ml})$ & $27,566.0 \pm 5,647.6$ & $24,921.2 \pm 7,821.5^{* *}$ \\
$\mathrm{IGF}-1(\mathrm{ng} / \mathrm{ml})$ & $596.6 \pm 104.1$ & $432.2 \pm 165.2^{*}$ \\
Cortisol $(\mu \mathrm{g} / \mathrm{dL})$ & $11.2 \pm 2.3$ & $15.3 \pm 4.3$ \\
\hline \multicolumn{3}{l}{ Values are means \pm SD } \\
EG: exercise group, CG: control group \\
$*:$ significantly different by the independent t-test, $* \mathrm{p}<0.05$, \\
$* * \mathrm{p}<0.01$
\end{tabular}

skeletal muscles as well as in various brain regions. Recently more research has been conducted to measure the reaction of human serum BDNF levels and targeted cognitive function of adult and elderly human subjects following long-term aerobic exercise and short sessions of aerobic exercise ${ }^{18-23)}$.

Uysal et al. reported that when the rats performed regular aerobic exercises the density of hippocampal neurons in rats increased $^{24)}$. According to Seifert et al., seven adult male subjects performed 12 weeks of endurance aerobic exercise and as a result BDNF serum significantly increased ${ }^{25)}$. Griffin et al. examined the effects of both short and long-term aerobic exercise on adolescents, whose brains are thought to still be undergoing significant development ${ }^{21)}$. They showed enhanced BDNF expression as a result of a single session of aerobic exercise, and a higher level of enhancement after the long-term aerobic exercise. It has also been reported that endurance exercise increases BDNF protein expression in the skeletal muscle of rodents ${ }^{26}$. Thomas et al. reported increases in the amount of BDNF as a result of long term regular exercise both when measured, during the exercise and at rest compared to groups that did not exercise at all ${ }^{3)}$.

In this study, after 8 weeks of regular aerobic exercise, the exercise group showed significantly increased serum BDNF expression levels, and a significant difference compared to the control group. In the study of Erickson et al., 120 elderly subjects performed 40 minutes of walking exercise (50-60\% intensity) for 7 weeks, and they demonstrated, significant increases in maximal oxygen uptake, serum BDNF, cognitive ability, and the size of the hippocampus ${ }^{20)}$. Also recent studies have reported the tendency of BDNF to increase at rest when endurance aerobic exercise was performed ${ }^{11,20,25,27,28)}$.

However, a study by Ferris et al. reported that cycling for a duration of 30 minutes at an intensity of $55 \% \mathrm{VO} 2 \mathrm{max}$ ( $20 \%$ below the lactate threshold) did not affect serum BDNF concentrations $^{29}$ ). We believe the, increases in serum BDNF levels at rest and after regular aerobic exercise are related to the intensity of the exercise, and a threshold intensity of $60 \% \mathrm{VO} 2 \mathrm{max}$ seems necessary to elicit a response in BDNF levels. More research should be done to further elucidate the relationship between exercise intensity and BDNF expression in response to exercise.

Griffin et al. studied the effects of both short- and long-term exercise ${ }^{21}$, examining changes in serum BDNF levels and cognitive performance. They included the use of a Face-Name matching task test and a Colour-Word test for cognitive performance evaluation (memory). Only the group 
which conducted 5 weeks of regular aerobic exercise showed a significant improvement in the Face-Name matching task test. Previous studies have failed to identify a relationship between the level of expression of BDNF and improvement in brain function in humans. Therefore, future studies relating the expression of BDNF and measures of brain function should also consider the effects of fifferent levels of exercise intensity on functional improvements as well as BDNF.

IGF-1 (insulin-like growth factor 1) is reported to be a carrier located in the upper part of a signaling pathway which induces the expression of BDNF. IGF-1 has been reported to be a factor contributing to neural cell growth, differentiation and survival, and it shows increases in expression in the brain and periphery in response to various forms of exercise ${ }^{12)}$.

Previous studies of the relationship between exercise and IGF-1 have reported that growth hormone increased due to regular aerobic exercise through the promotion of IGF1 synthesis in cells. It was reported that IGF-1 increased through an interaction with a variety of cells in the liver ${ }^{30)}$. In this study, 8 weeks of regular aerobic exercise resulted in a significant increase in serum IGF-1 expression levels postintervention, and the exercise group also showed significant differences from the group that did not exercise regularly.

In general, skeletal muscle growth and atrophy is regulated by insulin-like growth factor- ${ }^{31)}$. Lee and Rhyu reported that IGF-1 induced changes in the nervous system through aerobic exercise, which is a necessary condition for increased BDNF expression. They also showed that IGF-1 was a carrier located in the upper part of a signaling pathway which regulates the expression of $\mathrm{BDNF}^{32}$ ). Also, Larnon, Avitzur and Klinger reported that physical activity acted in combination with growth hormones and intermediate mediators to elicit changes in BDNF expression. They further reported that when children or young people are at rest, physical activity-associated changes in growth hormone induce increases in the level of IGF-1 through interactions with liver cells, which are important for protein synthesis, bone growth, and cell proliferation ${ }^{33)}$.

Cortisol is a stress hormone secreted from the adrenal cortex of the kidneys, and it is expressed in response to external stimuli which induce psychological stress, and plays a role in increasing blood pressure and glucose levels, enabling the body to produce maximum energy as a part of the stress response mechanism.

A study of the relationship between exercise and cortisol showed that short-term medium to low intensity strength exercises did not change plasma cortisol levels or may have even slightly reduced these levels, whereas high-intensity exercises increased plasma cortisol levels in the body ${ }^{34)}$.

In the present study, the group which performed regular aerobic exercise for 8 weeks showed decreased blood plasma cortisol levels, but the difference was not statistically significant. We believe this shows that while stress-induced exercise affects the expression of cortisol, as described in the murine studies of Zheng et al., the negative relationship between BDNF and cortisol is likely the result of changes in cortisol due to stress rather than the exercise performed ${ }^{16)}$.

This study was conducted on adolescent subjects, whose brains were still undergoing development, with the purpose of identifying the effect of an 8-week aerobic exercise protocol on the expression of BDNF, IGF-1 and cortisol. The results of this study suggest that chronic aerobic exercise has a positive effect, enhancing resting serum BDNF and IGF-1 expression in adolescents whose brains are still developing.

\section{REFERENCES}

1) Mizuno M, Yamada $\mathrm{K}$, Olariu A, et al.: Involvement of brain-derived neurotrophic factor in spatial memory formation and maintenance in a radial arm maze test in rats. J Neurosci, 2000, 20: 7116-7121. [Medline]

2) Soya $H$, Nakamura $T$, Deocaris CC, et al.: BDNF induction with mild exercise in the rat hippocampus. Biochem Biophys Res Commun, 2007, 358: 961-967. [Medline] [CrossRef]

3) Seifert T, Brassard P, Wissenberg M, et al.: Endurance training enhances BDNF release from the human brain. Am J Physiol Regul Integr Comp Physiol, 2010, 298: R372-R377. [Medline] [CrossRef]

4) Rice D, Barone S Jr: Critical periods of vulnerability for the developing nervous system: evidence from humans and animal models. Environ Health Perspect, 2000, 108: 511-533. [Medline] [CrossRef]

5) Cotman CW, Berchtold NC: Exercise: a behavioral intervention to enhance brain health and plasticity. Trends Neurosci, 2002, 25: 295-301. [Medline] [CrossRef]

6) Russo-Neustadt A, Ha T, Ramirez R, et al.: Physical activity-antidepressant treatment combination: impact on brain-derived neurotrophic factor and behavior in an animal model. Behav Brain Res, 2001, 120: 87-95. [Medline] [CrossRef]

7) Kim G, Kim E: The effects of antecedent exercise on motor function recovery and brain-derived neurotrophic factor expression after focal cerebral ischemia in rats. J Phys Ther Sci, 2013, 25: 553-556. [Medline]

8) Sairanen M, Lucas G, Ernfors P, et al.: Brain-derived neurotrophic factor and antidepressant drugs have different but coordinated effects on neuronal turnover, proliferation, and survival in the adult dentate gyrus. J Neurosci, 2005, 25: 1089-1094. [Medline] [CrossRef]

9) Pyun MY, Cho HS, Jeon JY, et al.: Effect of aerobic exercise on factors relative to the brain nerve growth in girls. J Life Sci, 2010, 20: 948-954. [CrossRef]

10) Lessmann V, Brigadski $T$ : Mechanisms, locations, and kinetics of synaptic BDNF secretion: an update. Neurosci Res, 2009, 65: 11-22. [Medline] [CrossRef]

11) Zoladz JA, Pilc A, Majerczak J, et al.: Endurance training increases plasma brain-derived neurotrophic factor concentration in young healthy men. $\mathrm{J}$ Physiol Pharmacol, 2008, 59: 119-132. [Medline]

12) Carro E, Trejo JL, Busiguina $S$, et al.: Circulating insulin-like growth factor I mediates the protective effects of physical exercise against brain insults of different etiology and anatomy. J Neurosci, 2001, 21: 5678-5684. [Medline]

13) Arsenijevic $Y$, Weiss S: Insulin-like growth factor-I is a differentiation factor for postmitotic CNS stem cell-derived neuronal precursors: distinct actions from those of brain-derived neurotrophic factor. J Neurosci, 1998, 18: 2118-2128. [Medline]

14) Reinhardt RR, Bondy CA: Insulin-like growth factors cross the bloodbrain barrier. Endocrinology, 1994, 135: 1753-1761. [Medline]

15) Gould E, McEwen BS, Tanapat $P$, et al.: Neurogenesis in the dentate gyrus of the adult tree shrew is regulated by psychosocial stress and NMDA receptor activation. J Neurosci, 1997, 17: 2492-2498. [Medline]

16) Zheng K, Shea PY, Le L, et al.: The effects of voluntary, involuntary, and forced exercise on Brain-Derived Neurotrophic Factor and Motor function recovery: a rat brain ischemia model. PLoS ONE, 2010, 6: e16643.

17) American College of Sports Medicine: ACSM's guidelines for exercise testing and prescription, 8th ed. Philadelphia: Lippincott Williams \& Wilkins, 2010.

18) Goekint M, De Pauw K, Roelands B, et al.: Strength training does not influence serum brain-derived neurotrophic factor. Eur J Appl Physiol, 2010, 110: 285-293. [Medline] [CrossRef]

19) Bos I, Jacobs L, Nawrot TS, et al.: No exercise-induced increase in serum BDNF after cycling near a major traffic road. Neurosci Lett, 2011, 500: 129-132. [Medline] [CrossRef]

20) Erickson KI, Voss MW, Prakash RS, et al.: Exercise training increases size of hippocampus and improves memory. Proc Natl Acad Sci USA, 2011, 108: 3017-3022. [Medline] [CrossRef]

21) Griffin ÉW, Mullally S, Foley C, et al.: Aerobic exercise improves hippocampal function and increases BDNF in the serum of young adult males. Physiol Behav, 2011, 104: 934-941. [Medline] [CrossRef] 
22) Heyman E, Gamelin FX, Goekint M, et al.: Intense exercise increases circulating endocannabinoid and BDNF levels in humans-possible implications for reward and depression. Psychoneuroendocrinology, 2012, 37: 844-851. [Medline] [CrossRef]

23) Nofuji Y, Suwa M, Moriyama Y, et al.: Decreased serum brain-derived neurotrophic factor in trained men. Neurosci Lett, 2008, 437: 29-32. [Medline] [CrossRef]

24) Uysal N, Tugyan K, Kayatekin BM, et al.: The effects of regular aerobic exercise in adolescent period on hippocampal neuron density, apoptosis and spatial memory. Neurosci Lett, 2005, 383: 241-245. [Medline] [CrossRef]

25) Seifert T, Brassard P, Wissenberg M, et al.: Endurance training enhances BDNF release from the human brain. Am J Physiol Regul Integr Comp Physiol, 2010, 298: R372-R377. [Medline] [CrossRef]

26) Gómez-Pinilla F, Ying Z, Opazo P, et al.: Differential regulation by exercise of BDNF and NT-3 in rat spinal cord and skeletal muscle. Eur J Neurosci, 2001, 13: 1078-1084. [Medline] [CrossRef]

27) Ruscheweyh R, Willemer C, Krüger K, et al.: Physical activity and memory functions: an interventional study. Neurobiol Aging, 2011, 32: 1304 1319. [Medline] [CrossRef]

28) Lee SS, Yoo JH, Kang S, et al.: The effects of 12 weeks regular aerobic exercise on brain-derived neurotrophic factor and inflammatory factors in juvenile obesity and type 2 diabetes mellitus. J Phys Ther Sci, 2014, 26 : 1199-1204. [Medline] [CrossRef]

29) Ferris LT, Williams JS, Shen CL: The effect of acute exercise on serum brain-derived neurotrophic factor levels and cognitive function. Med Sci Sports Exerc, 2007, 39: 728-734. [Medline] [CrossRef]

30) Fan J, Molina PE, Gelato MC, et al.: Differential tissue regulation of insulin-like growth factor-I content and binding proteins after endotoxin. Endocrinology, 1994, 134: 1685-1692. [Medline]

31) Tomori K, Kobayash R, Koseki T, et al.: Effect of neuromuscular electrical stimulation of denervated muscle on the mRNA expression of IGFs in rat skeletal muscle and sciatic nerve. J Phys Ther Sci, 2009, 21: 269-273. [CrossRef]

32) Lee KJ, Rhyu IJ: Effects of exercise on structural and functional changes in the aging brain. J Korean Med Assoc, 2009, 52: 907-919. [CrossRef]

33) Laron Z, Avitzur Y, Klinger B: Carbohydrate metabolism in primary growth hormone resistance (Laron syndrome) before and during insulinlike growth factor-I treatment. Metabolism, 1995, 44: 113-118. [Medline] [CrossRef]

34) Rojas Vega S, Strüder HK, Vera Wahrmann B, et al.: Acute BDNF and cortisol response to low intensity exercise and following ramp incremental exercise to exhaustion in humans. Brain Res, 2006, 1121: 59-65. [Medline] [CrossRef] 